\title{
Injectable Methylcellulose and Hyaluronic Acid Hydrogel containing silver nanoparticles for their effective anti-microbial and wound healing activity in nursing care for burn injuries in children
}

Jianye Jiang ( $\sim$ jianye.j@yahoo.com )

Chengyang District People's Hospital of Qingdao https://orcid.org/0000-0001-7636-7237

Xiaojing Han

Chengyang District People's Hospital of Qingdao

Huan Xu

Chengyang District People's Hospital of Qingdao

\section{Research Article}

Keywords: AgNPs, MC-HA hydrogels, Antibacterial activity, Wound, Nursing care children

Posted Date: May 14th, 2021

DOI: https://doi.org/10.21203/rs.3.rs-490312/v1

License: (c) (i) This work is licensed under a Creative Commons Attribution 4.0 International License.

Read Full License 


\section{Abstract}

Currently, the synthesis of silver nanoparticles (AgNPs) was utilized for various life-saving biomedical applications. Herein, we report the synthesis and characterization of methylcellulose and hyaluronic acid (MC-HA) hydrogels containing AgNPs dressing materials were investigated for their wound healing efficiency to treat surgical excision wounds and the findings were studied and discussed. The effect of the ratio of AgNPs and MC-HA hydrogels on the gelation time, in vitro degradation, and equilibrium swelling of MC-HA/AgNPs hydrogels was examined. The prepared MC-HA hydrogels containing AgNPs were studied using various characterization techniques such as UV-Visible spectroscopy, Scanning electron microscopy (SEM), Transmission electron microscopy (TEM), Fourier transform infrared (FTIR) spectroscopy, and X-ray diffraction (XRD). The MC-HA/AgNPs showed excellent antimicrobial activity against $S$. aureus and E. coli, respectively. Additionally, the superior wound recovering potential of AgNPs with MC-HA hydrogels compared to conventional formulations was illustrated in vitro in animals utilizing visual observations and histological study. The MC-HA/AgNPs hydrogels showed excellent antimicrobial activity and burn wound healing. Therefore, these MC-HA hydrogels containing AgNPs have great potential medicinal applications in nursing care in children after surgery.

\section{Introduction}

Wound healing involves a series of responses that lead to tissue regeneration and wound dressing biomaterials aid this process by providing an adequate bio-environment and keeping cells in the wound site intact [1]. Because of the chronicity, systemic infection from the wound area, known as wound infection, is the leading cause of death in patients recovering from burns. Damaged tissue provides a suitable habitat for drug bacterial development in a few patients with an acute injury, resulted in diseases that may be difficult to treat [2]. Wound healing, in conjunction with tissue repair, is an essential and complex process that ensures recovery, while defective wound healing can pose several therapeutic challenges $[3,4]$. Numerous wound healing agents have become effective in recent years, with nanoparticle-controlled chemical delivery systems serving as an active technique in the delivery of antibiotics into skin tissue being one of them. Furthermore, wound dressing products should maintain a stable healing state to protect the wound from microbial infections. It should also contain wound exudate while allowing for a sufficient exchange of gases. Non-allergic, non-toxic, and biomimetic wound dressings can stimulate the release of effector cells [5]. Furthermore, wound dressing agents should be antibacterial effective, and simple to remove without producing wound damage [6].

The most recent advancements use noble metal antimicrobial drugs against certain burning diseases, with silver being the most prominent [7]. Silver (Ag) was used for its therapeutic and antibacterial effects in contrast to various inflammatory diseases before the advent of injection [8]. Silver nanoparticles (AgNPs) are well-known as more effective wound healing resources than bulk Ag alloy, and they've been widely used in sepsis prevention and treatment $[9,10]$. The main advantages of AgNPs in attractive wound healing action are their increased surface area and high surface atom proportion [11]. AgNPs are typically neutralized by anion in body fluids, so they can cause cosmetic abnormalities over time and can 
halt the healing process through fibroblast and epithelial cytotoxic effects. Despite these flaws, Ag remains the most widely used topical antimicrobial Ag delivery method because better solutions are inaccessible. Wound healing is considered as a complex, multistep mechanism involving the integration of the action of various tissues and cell lineages. The use of nanoparticles in skin treatment is perhaps the most well-documented as AgNPs. The interaction of metal ions with cells on the surface of burn spots results in the development of a stable complex, which leads to the production of a powerful healing agent. AgNPs have been widely used in the treatment of wounds and burns in children due to these effects. AgNPs mediated hydrogels were also confirmed to be widely used in pediatric wound care dressing components, with significant wound healing reliability $[12,13]$.

Injectable hydrogels consisting of small polymers and microparticles have been used in several biological applications [14, 15]. Injectable, biodegradable polymers could be used as drug and cell carriers for tissue engineering, allowing for simple and standardized drug or cell delivery in any size or shape defect $[15,16]$. Cellulose substitutes are sources of biocompatible composites, and aqueous solutions of methylcellulose (MC) is a polymer resulting from cellulose by incomplete replacement of hydrophilic - $\mathrm{OH}$ with hydrophobic $-\mathrm{OCH}_{3}$ groups have recently been used $[17,18]$. As $\mathrm{MC}$ is soluble in an aqueous medium, it creates contrary thermo-responsive smart hydrogels that induce a sol-gel transformation when heated, which is consistent with a conversion from hydrophilic nature ( $\mathrm{H}$-bonds between water and -OH groups of MC) at higher temperatures [19]. By incorporating mono and divalent salts or mixing it with other composites such as poly(acrylic acid) chitosan, carboxymethyl cellulose, and or hyaluronic acid (HA), the gelation temperature of MC may be lowered to physiological levels [20-22]. Hyaluronic acid (HA) plays an important role in wound healing, cell-matrix interaction, and has the unique ability to fill up the surrounding space, thus invading the ECM [23]. When HA is oxidized, the C-C bonds of the cisdiol groups in the polymer chains are sliced, resulting in sensitive aldehyde compounds, which can form chemical crosslinks with amino structures through Schiff's base linkage [24]. MC has a large number of functional groups, which provide enough sites for metal Nanoparticles to be stabilized by forming a coordination bond $[25,26]$. Green synthesis was used to make MC-capped silver nanoparticles with a spherical form and sizes ranging from $3 \mathrm{~nm}$ to $17 \mathrm{~nm}$ [27-29]. Similarly, AgNPs formed from MC-containing bacterial nanocomposites were found to be highly stabilized by the functional groups of $\mathrm{MC}$ and bacterial nanocellulose. Another study found that MC stabilized silver nanodiscs made through the seed-mediated path, proving that MC could be used as a specific precursor for AgNPs stabilization [30].

This study aimed to develop MC-HA hydrogel that could be formed in situ, the effects of varying the ratio of AgNPs on gelation time, equilibrium swelling, and in vitro degradation. The as-prepared materials were characterized by various instrumentation techniques such as UV-Visible, FTIR, XRD, SEM, and TEM. To the best of our knowledge, the antibacterial and wound healing applications of $\mathrm{MC} / \mathrm{HA}$ hydrogel containing AgNPs have not been recorded. As a result, we developed AgNPs-containing dressing materials as effective antimicrobial agents against $S$. aureus and $E$. coli, and we explored their wound healing efficacy. Efficient in vitro and in vivo research was conducted in this study to prove the wound healing impact of AgNPs formulations on rats' skin. 


\section{Materials And Methods \\ 2.1. Materials}

Methylcellulose (MC), hyaluronic acid sodium (HA), and silver nitrate were obtained from Sigma-Aldrich. All chemicals and reagents were used as received without purification. Throughout the experiment, double distilled water was used.

\subsection{Preparation of MC-HA hydrogels containing AgNPs}

The following are the steps for the synthesis of MC-HA-based formulations. $0.5 \mathrm{~g}$ of MC was dissolved in $100 \mathrm{ml}$ distilled water in a $250 \mathrm{~mL}$ round bottom flask in a standard synthesis. The hydrogels were made by dissolving HA solutions in PBS at a concentration of $0.25 \mathrm{~g}$ in $50 \mathrm{~mL}$ and mixing them. Half of the solvent (PBS) was held at $0^{\circ} \mathrm{C}$ and the other half was heated to boiling. The resulting solution was put in an ice bath while being stirred. The solution was held at $4^{\circ} \mathrm{C}$ overnight to ensure maximum solubility. Then, using a magnetic stirrer, $150 \mathrm{mg} / \mathrm{mL}$ silver nitrate powder was applied to the $5 \%$ wt aqueous MC-HA solution and gently stirred overnight at room temperature. The silver ions $\left(\mathrm{Ag}^{+}\right)$are stabilized in the hydrogel pores during swelling in the silver nitrate solution. The metal ions are attached to the MC-HA hydrogel networks' functional groups $\left(-\mathrm{NH},-\mathrm{OCH}_{3},-\mathrm{OH}\right.$, and $\left.-\mathrm{COO}\right)$. As a result, significant quantities of silver ions can be captured in the MC-HA hydrogel networks cavities. The final concentrations of the silver nitrate were 0.5 and $1.0 \mathrm{wt} \%$. The crosslinked hydrogels were designed by mixing MC/HA with different Ag concentrations (0.5-2.0 wt\%) were named MC/HA/AgNPs-0.5, MC/HA/AgNPs-1.0, and $\mathrm{MC} / \mathrm{HA} / \mathrm{AgNPs}-2.0$, respectively.

\subsection{Determination of gelation time}

The inverted tube method was used to determine gelation time. The synthesized AgNPs were analyzed and after washed the MC-HA hydrogel received at $37^{\circ} \mathrm{C}$, the MC-HA hydrogel was immersed in distilled water and separated by centrifugation at $2500 \mathrm{rpm}$ for $3 \mathrm{~min}$ and controlled by continuous inversion. To see if the gel flowed, the tube was tilted at 1, 3, 5, 7, and 10 min intervals. After three cycles of this procedure, the AgNPs were lyophilized after gelation at $37^{\circ} \mathrm{C}$.

\subsection{In vitro degradation}

Weight loss was also investigated using MC-HA and MC-HA/AgNPs hydrogels were examined. The weight loss of initial weighted hydrogels $\left(\mathrm{W}_{0}\right)$ was determined as a function of time incubated in PBS at $37^{\circ} \mathrm{C}$. Samples were gathered from the medium at regular intervals, washed by distilled water, dried under vacuum, and processed for study. The following equation was used to calculate in vitro degradation:

$\%$ Degradation $\left.(\mathrm{t})=\left[\mathrm{W}_{\mathrm{d}(0)}\right)-\mathrm{W}_{\mathrm{d}(\mathrm{t})}\right] / \mathrm{W}_{\mathrm{d}(0)}$

where $\mathrm{W}_{\mathrm{d}(0)}$ and $\mathrm{W}_{\mathrm{d}(\mathrm{t})}$ are the initial dry polymer mass and at time t.

\subsection{Equilibrium swelling}


The weights of MC-HA and MC-HA/AgNPs hydrogels were dissolved in PBS and held at $37^{\circ} \mathrm{C}$ for 2 hours before swelling equilibrium was achieved. The hydrogels were collected at fixed intervals and weighted with a microbalance after the excess water on the surfaces was absorbed with filter paper. The following equation was used to determine the equilibrium swelling ratio (ES):

$E S=\left(W_{s}-W_{d}\right) / W_{d}$

where $W_{s}$ and $W_{d}$ are the MC-HA and MC-HA/AgNPs hydrogels weight swelling state and at the dry state of the equilibrium.

\subsection{Spectral and morphological characterizations of hydrogels}

\subsubsection{UV-vis}

Diluted MC-HA and MC-HA/AgNPs hydrogels solution containing Ag NPs was measured by UV-vis spectrophotometer (Shimadzu, model UV-1800, Kyoto, Japan) used to record the UV-vis spectra.

\subsubsection{Scanning Electron microscopy (SEM)}

After gelation, scanning electron microscopy (SEM) was used to deliberately lyophilize MC-HA and MCHA/AgNPs hydrogels to ensure their 3D porous structure. The hydrogels were freeze-dried and then goldcoated using a Cressington 108 Auto (Cressington, Watford UK). Using Image J Software, 15

representative pores were measured to determine the average size of pores on the device surfaces (Java 1.8.0).

\subsubsection{Transmission Electron microscopy (TEM)}

A Transmission Electron Microscope Hitachi HT7700 was used to examine the prepared AgNPs (Tokyo, Japon). The AgNPs were released from the MC-HA hydrogels by hydrating them with three volumes of distilled water and sonicating them for five minutes in a bath at a frequency of about $20 \mathrm{kHz}$. A drop of the suspension was placed on a lacy carbon-coated $\mathrm{Cu}$ grid after a powdered sample was mixed with ethanol using a $200 \mathrm{kV}$ voltage.

\subsubsection{FT-IR spectroscopic analysis}

FT-IR measurements were obtained using a Nicolet FT-IR 5700 spectrophotometer (Thermo Fisher Scientific, Waltham, MA, USA) at ambient conditions. The MC-HA, AgNPs, and MC-HA/AgNPs hydrogels samples were observed in the wavelength range of $4000-400 \mathrm{~cm}^{-1}$.

\subsubsection{X-ray diffraction measurements}

X-ray diffraction (XRD) pattern on MC-HA, AgNPs, and MC-HA/AgNPs hydrogels were carried out using a D8 Advance diffractometer (Bruker AXS, Inc., Madison, WI, USA) with Cu set and K radiation (= $0.154 \mathrm{~nm}$ ) 
at $30 \mathrm{kV}$ and $40 \mathrm{~mA}$ on MC-HA, AgNPs, and MC-HA/AgNPs hydrogel. The scan speed was 2 degrees per minute, and the spectra of $2 \theta$ ranged from 10 to 80 degrees.

\subsection{Antimicrobial activity}

The antibacterial function of MC-HA and MC-HA/AgNPs hydrogels were quantified using the viable cell count method against gram-positive Staphylococcus aureus and gram-negative Escherichia coli. The LB medium was separated, the bacteria were washed three times with PBS (pH 7.4), and 1.0 ml of MC/HA and MC-HA/AgNPs hydrogels were applied to change the $2 \%$ test sample concentration. The surface of

hydrogels and control hydrogels were uniformly coated with $10 \mu \mathrm{L}$ of bacterial suspension in PBS $\left(1 \times 10^{6}\right.$ $\mathrm{CFU} / \mathrm{mL}$ ), and these samples were incubated at $37^{\circ} \mathrm{C}$ for 1 hour. As a result, $10 \mathrm{~mL}$ of bacterial dispersion was mixed with $7 \mathrm{~mL}$ of sterilized culture medium and applied to the hydrogel with and without Ag NPs. The bacterial sample was diluted with PBS before being plated on LB agar and incubated for 24 hours at $37^{\circ} \mathrm{C}$. After incubation, the number of the colony was counted and the antimicrobial activity of the MC-HA and $\mathrm{MC} / \mathrm{HA} / \mathrm{AgNPs}$ hydrogels was converted to the colony-forming unit (CFU/mL).

\subsection{In vivo animal experiment}

The Animal Research Committees of Chengyang District People's Hospital approved all animal procedures. The twelve young Sprague-Dawley male rats (120 g) were randomly divided into three groups: control, MC-HA hydrogels, and MC/HA/AgNPs hydrogels group, each group was held in separate cages and fed standard rodent feed and water ad libitum at a temperature of $25^{\circ} \mathrm{C}$ under sanitary conditions. A surgical blade was used to construct a wound with a surface area of $1.5 \times 1.5 \mathrm{~cm}^{2}$ for each rat in the cleaned area. Rats were anesthetized with a $1.0 \mathrm{~mL} / \mathrm{kg}$ intraperitoneal injection of $3 \%$ pentobarbital sodium solution) before surgery. The wound was applied to each animal with enough test samples. Group 3 animals were given an AgNPs gel containing a similar concentration of $1.0 \mathrm{mg}$ AgNPs $(\mathrm{Ag})$ per $\mathrm{cm}^{2}$ of the wounded region. Animals are anesthetized with a mixture of xylazine and ketamine at 10 and $80 \mathrm{mg} / \mathrm{kg}$, then depilated before burning on the anterior-dorsal side. Subsequently, the paste of the above four freshly prepared dressings was used to tightly cover the surface of the wound, respectively, and the PBS was employed for the control group rats. The dressings on the wound were changed every day. Wound healing effect was observed and evaluated after 2, 4, 8, and 16 days, respectively.

\subsection{Histological studies}

The animals in both the control and experimental groups were examined on the 2, 4, 8, and 16 days after the wound was created by extracting tissue from the wound site of individual mice and treating it in a $4 \%$ paraformaldehyde solution at room temperature. After that, the tissue samples were cleaned in xylene and coated in paraffin wax. The fixed tissue was then soaked in paraffin and cross-sectioned into $4 \mathrm{~mm}$ thick slices, which were then stained with hematoxylin and eosin ( $\mathrm{H} \& \mathrm{E})$. Histological slides were analyzed by optical microscopy under 20x magnification (Olympus Bx51).

\subsection{Statistical analysis}


Data were analyzed using the Statistica 7 software. Results were analyzed by triplicate and the results are reported as mean \pm standard deviation. The significance of the data was considered statistically different at $p<0.05$, using the one-way ANOVA and the Tukey test.

\section{Results And Discussions}

\subsection{Hydrogel formation mechanisms}

Water molecules are known to interact with the hydrophobic methoxyl $\left(-\mathrm{OCH}_{3}\right)$ groups of methylcellulose (MC) through hydrogen bonding, forming cage-like structures that surround the $-\mathrm{OCH}_{3}$ groups, effectively shielding them from the hydrophilic environment and causing $M C$ to become water-soluble. As a result, intra- and intermolecular chain hydrophobic interactions form, resulting in gelation as the number of interactions increases, essentially creating a broad 'hydrophobicity cross-linked' network [31]. The involvement of - $\mathrm{NH}$ and - $\mathrm{COO}$ - ionizable groups, as well as hydrogen interactions produced by the functional - $\mathrm{COOH}$ and - $\mathrm{OH}$ groups, contribute to the formation of hydrogel (Scheme 1). Following hydrogel processing, silver nitrate was added to the MC-HA hydrogel in various concentrations $(0.5,1.0$, and 2.0 percent $\mathrm{w} / \mathrm{w}$ ), resulting in surface plasmon resonance, indicating nanoparticle formation. $\mathrm{Ag}^{+}$ also has a strong oxidizing effect on organic compounds. The presence of $-\mathrm{OH}$ and $-\mathrm{COOH}$ groups in the polymeric units of the MC-HA hydrogel favors the synthesis of $\mathrm{Ag}^{+}$chelate by the adjacent $-\mathrm{OCH}_{3},-\mathrm{NH}$, $\mathrm{OH}$, and $-\mathrm{COOH}$ groups of $\mathrm{MC}$ and $\mathrm{HA}$ [32].

\subsection{Gelation time, in vitro degradation, and equilibrium swelling of hydrogels}

The gelation rate of MC-HA hydrogels containing AgNPs was observed at ambient conditions. When 50 $\mathrm{mg} / \mathrm{mL}$ MC-HA hydrogels were mixed with three different AgNPs weight ratios $(0.5,1.0$, and $2.0 \% \mathrm{w} / \mathrm{w})$, gelation occurred within 8 min (Fig. 1a). Apparently, as the concentration of AgNPs (2.0\% w/w) increases in the MC-HA hydrogels, the required time for gelation decreases [33]. The gelation rate of MC-HA/AgNPs$2.0 \%$ hydrogel was the fastest, which exhibited a substantially higher gelation rate than MC-HA/AgNPs$1.0 \%$ and MC-HA/AgNPs- $0.5 \%(\mathrm{p}<0.05)$. In vitro degradation of hydrogels was observed as a function of incubation time in PBS at $37^{\circ} \mathrm{C}$, as shown in Fig. $1 \mathrm{~b}$. A rise in crosslinking density leads to a decrease in water content and a loss of mass weight. The weight loss was significantly influenced by the $2 \% \mathrm{w} / \mathrm{w}$ ratio of AgNPs in the MC-HA hydrogels. Owing to less crosslinking, the hydrogels with a ratio of $0.5 \%$ and $1.0 \%$ lost weight slightly faster and dissolved on day 1 to 10 days, respectively. The other hydrogels slowly lost weight for up to 14 days [34]. The weight remaining ratios of AgNPs in the MC-HA hydrogels at day 14 were $54.2 \%, 62.4 \%, 71.7 \%$, and $82.5 \%$, respectively. Even though some studies claim that the crosslinking structure of HA is unstable, we discovered that the MC-HA/AgNPs hydrogels remained stable in PBS for 14 days, indicating that the hydrolysis rate of MC-HA/AgNPs is slow under physiological environment. The improved degradation rate of the sample with AgNPs could be described by the morphology features like porous gel structure of MC-HA hydrogels. Thus, the degradation rate for MC- 
$\mathrm{HA} / \mathrm{AgNPs}-2.0 \%$ by the greater porosity should be faster than MC-HA/AgNPs- $0.5 \%$ and MC-HA/AgNPs$1.0 \%$.

The swelling ratio was improved along with the increase of AgNPs content in the MC-HA hydrogels, which developed water-soluble after a $2 \mathrm{~h}$ incubation [35]. The swelling value grew rapidly as the AgNPs content increased from $0.5-2.0 \%(p<0.05)$ (Fig. 1c). The swelling properties of the MC-HA hydrogels are critical for material exchange when used as injectable hydrogels for biological applications. Both MC and HA have a large number of hydrophilic groups, such as $-\mathrm{OCH}_{3},-\mathrm{NH},-\mathrm{OH}$, and $-\mathrm{COOH}$, that can easily hydrate with water [36]. The amount of AgNPs in the MC-HA used in the hydrogel synthesis has a major effect on the swelling properties of the hydrogels [37].

\subsection{UV-vis spectra of MC-HA hydrogel containing AgNPs}

The optical properties of the MC-HA hydrogels containing AgNPs were estimated by UV-Vis spectroscopy (Fig. 2). In an aqueous solution, silver nitrate $\left(\mathrm{AgNO}_{3}\right)$ is dissociated into silver $\left(\mathrm{Ag}^{+}\right)$and nitrate $\left(\mathrm{NO}_{3}{ }^{-}\right)$ ions. Figure 2 depicts the shift in AgNPs absorbance as a function of ratio $(0.5,1.0$, and $2.0 \%)$. It determines the surface plasmon band develops as a function of $\mathrm{Ag}+$ concentration [38]. The maximum absorbance wavelength at $418 \mathrm{~nm}$, and it largely depends on the size and interaction between the particles. The absorbance strength of the MC-HA hydrogels solution also increased, implying that the amount of AgNPs in the solution increased as well [39]. Analyzing the spectral properties of AgNPs incorporated into MC-HA hydrogels will provide a wealth of knowledge about the physical state of the nanoparticles. Other researchers produced AgNPs-containing hydrogels and achieved similar results.

\subsection{Morphology of MC-HA hydrogel containing AgNPs}

The surface morphology, size, and shape of MC-HA hydrogel containing AgNPs were studied using SEM and TEM analysis. (Figs. 3 and 4). The prepared MC-HA hydrogel exhibited a honeycomb-like threedimensional porous structure [40]. There were no AgNPs in MC-HA hydrogel (Fig. 3a), and AgNPs (0.5, 1.0, and $2.0 \%$ ) were observed in MC-HA hydrogel (Fig. 3b-d). As shown in Fig. 3b-d, the MC-HA hydrogel incorporating AgNPs had a remarkable pore size and an associated honeycomb structure. This suggests that the AgNPs were developed in situ and were uniformly distributed in the MC-HA hydrogel [41]. As the $\mathrm{Ag}^{+}$ions are captured, these types of assemblies with appropriate porosity play a critical role in allowing them to diffuse through the pores. Although providing enough surface and strength for cellular operation, a cross-linked network with optimum porosity facilitates improved cellular penetration and nutrients activities [42]. Similar findings have recently been published for films with honeycomb structures that have smaller holes and a more efficient porous structure.

The spectral properties are consistent with low nanoparticle size. Further, the morphology of prepared MC-HA hydrogel containing AgNPs was deliberate by using TEM image and histogram investigation (Fig. 4). Figure 4a, shows an amorphous morphology of MC-HA hydrogel. Furthermore, as shown in Fig. 4b, the AgNPs in the MC-HA hydrogel are distinctly spherical and well-organized, distributed evenly, and widely spaced across the polymeric matrix [43]. HRTEM images showed that the proposed AgNPs 
were spherical, with well-ordered single crystals and visible lattice fringes (inset Fig. 4b) [44]. The average diameter of the synthesized MC-HA/AgNPs was measured to be $35 \mathrm{~nm}$ (Fig. 4c). The particle size determined by TEM was in strong agreement with the crystalline size, and this value was supported by $\mathrm{XRD}$ analysis measurements. With extended activities, the chemical interactions between molecules in such polymer dressing will maintain the sufficient release of AgNPs. As a result, formulations based on MC-HA hydrogels containing 2.0\% wt. AgNPs were considered for further research.

\subsection{FT-IR spectroscopic analysis}

FT-IR spectra of MC-HA hydrogel, AgNPs, and MC-HA hydrogel containing AgNPs are presented in Fig. 5a. FTIR spectra of MC show corresponding peaks at 3521, 2871, 1379, and $1039 \mathrm{~cm}^{-1}$, exposed the occurrence of $-\mathrm{OH}, \mathrm{C}-\mathrm{H}$, and $\mathrm{C}-\mathrm{O}$ group stretching vibration, respectively. MC in FTIR spectra usually present bands at $1458,1379,1319$, and $949 \mathrm{~cm}^{-1}$ ascribed to $\mathrm{C}-\mathrm{H}, \mathrm{CH}_{2}$, and $\mathrm{CH}_{3}$ groups stretching [45]. Figure 5a displays the FT-IR spectrum with several distinct peaks showing the development of the MC-HA hydrogel. There is a good signal from intensity vibration between 3048 and $3398 \mathrm{~cm}^{-1}$, which could be due to the $\mathrm{MC}$ alcohol and the hydrogels hydration grade. The characteristic signal of alkyl $\left(\mathrm{O}-\mathrm{CH}_{3}\right)$ stretching modes of the MC was seen at $2919 \mathrm{~cm}^{-1}$. Furthermore, at $2839 \mathrm{~cm}^{-1}$, the typical peak of the $\mathrm{MC}$ spectrum stretching band was observed. The signal at $1638 \mathrm{~cm}^{-1}$, which belongs to the covalent ester bonds developed between the alcohol of MC chains and the carboxyl group of HA, shows the crosslinking interaction between MC and HA [46]. The characteristic peaks of the MC-HA hydrogel have changed, and a few new peaks have appeared in the $1500-1600 \mathrm{~cm}^{-1}$ range. AgNPs had distinct peaks in the FTIR spectrum at $1538,1651,1228,2919,2849$, and $3288 \mathrm{~cm}^{-1}$. The vibrational characteristic peak of AgNPs was found in the $400-1000 \mathrm{~cm}^{-1}$ range. Because of the stretching vibration of $\mathrm{Ag}^{+}$in AgNPs, the peak appeared at $500 \mathrm{~cm}^{-1}$. When comparing the spectral properties of MC-HA/AgNPs to the MC-HA hydrogel, all of the standard peaks of MC, HA, and AgNPs were observed, but the above represent peaks were shifted to $3491,2931,1671,1549$, and $1331 \mathrm{~cm}^{-1}$ [28, 32]. Based on these findings, it was determined that the carbonyl, alkyl, and hydroxyl groups involved in the MC-HA hydrogel have a higher affinity for binding with metal ions, facilitating silver ion reduction into AgNPs.

\subsection{XRD patterns}

Figure $5 b$ shows the XRD patterns of MC-HA hydrogel, AgNPs, and MC-HA hydrogel containing AgNPs. The MC-HA hydrogel presented a characteristic diffraction peak at $2 \theta=27^{\circ}$ demonstrating the amorphous nature. The synthesized AgNPs displayed a strong intense peaks plane, which agrees to (111), (200), (220), and (311) considerations of face-centered cubic structure metallic silver correspondingly which were in approve with the JCPDS File No: 04-0783 demonstrating the crystalline nature of the AgNPs [47]. The peaks corresponding to the MC-HA and AgNPs were identical in XRD patterns of MC-HA/AgNPs, but the peak positions were slightly different. The partial surface oxidation of AgNPs (formation of the AgO phase) during the composition of MC-HA/AgNPs was due to the subsequent peaks observed at 28, 33, 37, and $45^{\circ}$. Furthermore, the XRD patterns showed that the MC-HA hydrogel incorporating AgNPs was successfully formed without any other contaminants. As a result of the decreased intensity peaks, AgNPs 
on the MC-HA hydrogel have been effectively integrated [48]. The particle size of the AgNPs was calculated using the Debye-Scherrer equation and was found to be about $27 \mathrm{~nm}$, which was in agreement with the TEM findings.

\subsection{Antibacterial activity of the MC-HA/AgNPs}

Antibacterial activity of the MC-HA hydrogel and MC-HA hydrogel containing AgNPs was observed by both bacteria namely $S$. aureus and E. coli. The control group and the MC-HA hydrogel were used as a reference. The MC-HA hydrogel with AgNPs had an excellent antibacterial activity of $99.6 \%$ regardless of the type of bacteria are listed in Table 1 [49-51]. The increased surface correlations between MCHA/AgNPs and bacteria may have caused this activity. Antibacterial activity against a variety of organisms is known for Ag compositions [52]. Sulfur-containing proteins are found in the bacterial cell membrane, and $\mathrm{Ag}^{+}$from AgNPs associates with these proteins in the cell. As compared to $E$. coli, the findings showed that MC-HA/AgNPs had the greatest antibacterial activity than $S$. aureus. This may be due to the influence of a double membrane in E. coli. The Ag ions released in the presence of oxygen/water were supposed to form a complex with bacteria and cause cell wall disruption [53]. The non-ionic and hydrophilic properties of the MC-HA hydrogel aided the easy release of AgNPs in this study. As a result, we conclude that the MC-HA hydrogels containing AgNPs have proved to be excellent and efficient antibacterial agents. Current literature confirms the antibacterial findings, suggesting that metallic nanoparticles not only minimize wound infection but also facilitate wound healing [54].

Table 1

The bacterial reduction rate of control, MC-HA hydrogel, and MC-HA hydrogels containing AgNPs.

\begin{tabular}{|lllll|}
\hline \multicolumn{3}{|l}{ Staphylococcus aureus } & Escherichia coli & \\
\hline & $\begin{array}{l}\text { No. of bacterial } \\
\text { after } 24 \mathrm{~h}\end{array}$ & $\begin{array}{l}\text { Bacterial } \\
\text { reduction rate }\end{array}$ & $\begin{array}{l}\text { No. of bacterial } \\
\text { after } 24 \mathrm{~h}\end{array}$ & $\begin{array}{l}\text { Bacterial } \\
\text { reduction rate }\end{array}$ \\
\hline Control & $2.0 * 10^{5}$ & - & $2.0 * 10^{5}$ & - \\
\hline MC-HA & $<40$ & 68.4 & $<40$ & 76.2 \\
\hline $\begin{array}{l}\text { MC- } \\
\text { HA/AgNPs }\end{array}$ & $<45$ & 89.2 & $<55$ & 92.1 \\
\hline
\end{tabular}

\subsection{In vivo wound healing effect}

Metal nanoparticles have been used extensively in biomedical, as well as as a wound-healing agent [1, 55]. In this study, we demonstrated for the first time the significant benefit of MC-HA hydrogel incorporating AgNPs in a rat tissue repair model. The wound healing ability of the established hydrogels was investigated for 16 days using a full-thickness rat cutaneous wound system, with the results shown in Fig. 6. As shown in Fig. 6a, wound surface images were taken regularly for both the control and experimental groups. The wound treated with MC-HA/AgNPs hydrogel, on the other hand, grew fresh skin and showed almost complete recovery after 16 days [56]. As shown in Fig. 6b, the MC-HA/AgNPs 
dressing group had a wound healing rate of $98.6 \%$, which is higher than the control (33.4\%) and MC-HA hydrogel $(69.1 \%)$ groups, suggesting that the synergistic effect $(p<0.05)$ contributed to its better healing capacity. On the 2, 4 and 8 postoperative days, the successful activity of the MC-HA hydrogel with the addition of AgNPs in the community responding to MC was observed. The successful behavior of the MC-HA/AgNPs hydrogel can be linked to the development of granulation tissue after 16 days [57]. The above experimental findings indicate that AgNPs treated wounds had a faster wound granulation tissue formation than the control group, which may be attributed to AgNPs ability to alter cytokine cascades and thus improve wound appearance $[58,59]$. As a result of the rational nature of such hydrogel dressings by chemical reactions, wound healing is improved. Furthermore, the exact mechanism involved in AgNPs wound-healing action was unknown. Due to the MC-HA hydrogel and AgNPs, MC-HA/AgNPs greatly improved wound healing performance.

\subsection{Histological investigations of MC-HA hydrogel containing AgNPs}

The use of AgNP-containing hydrogels facilitated histological improvements in the healing tissue throughout wound healing, such as earlier wound contraction growth and maturation. Histological examinations of burn injury sites treated with MC-HA hydrogel containing AgNPs incubated for 2, 4, 8, and 16 days are shown in Fig. 7. On day 16, a huge proportion of cells were found in the injected burn healing region, similar to the number found on days 2, 4 and 8. Additionally, the MC-HA and MCHA/AgNPs hydrogel groups were formed perfect and intact epidermis [60,61]. A few cells were identified in the burn wound healing region in the control groups. The presence of a larger number of intact cells in the dermis, which means fewer scars, was the most striking feature that distinguished AgNPs composite gel from marketed formulations [62].

At 14 days of incubation, the deeper granulation tissue-stained matured skin demonstrated in burn injures implanted by MC-HA/AgNPs hydrogel stained with Masson's trichrome stain than at 2, 4 and 8 days of incubation as shown in Fig. 7. Finally, the analysis of the thickest granulation tissue indicated that the MC-HA/AgNPs hydrogel had the most improved wound healing led to increase [11]. In specific, all of the in vivo wound healing test results, involving wound area and characteristics, morphology, new skin development area, epidermis thickness, and granulation tissue thickness, have shown that MC-HA-based hydrogels have a beneficial impact during the wound healing process [5].

\section{Conclusion}

In summary, the present investigation demonstrated that MC-HA hydrogel containing AgNPs could be improved spectral and morphological properties and applied as an effective antibacterial and wound healing process as nursing care of burn injury in children. The as-prepared AgNPs (diameter $\sim 35 \mathrm{~nm}$ ) and containing MC-HA hydrogel have been characterized by using UV-Vis, SEM, TEM, FTIR, and XRD analysis. It was proven due to the possible inter-chain interaction between MC and HA, the addition of AgNPs showed excellent stability on the gelation time, in vitro degradation, and equilibrium swelling properties. 
In vitro studies reveal that the MC-HA/AgNPs hydrogels possess an excellent antibacterial activity was confirmed by $S$. aureus and E. coli bacteria. Significantly, after 16 days of diagnosis with MC-HA/AgNPs dressing, in vivo examination of mice, cutaneous wound healing reveals an enhanced wound healing capacity with a high healing rate at $99.6 \%$. The biological findings showed that MC-HA/AgNPs hydrogels are highly beneficial for new skin development and blood supply regulation in burn injury treatment processes. These findings support the promise of such effective MC-HA/AgNPs hydrogels for the treatment of wound healing as well as burn injury nursing care in children.

\section{Declarations}

\section{Conflicts of Interest}

There are no conflicts to declare about this research investigation.

\section{References}

[1] A. Naskar, K.S. Kim, Recent advances in nanomaterial-based wound-healing therapeutics, Pharmaceutics. 12 (2020). https://doi.org/10.3390/pharmaceutics12060499.

[2] P.G. Bowler, B.I. Duerden, D.G. Armstrong, Wound microbiology and associated approaches to wound management, Clinical Microbiology Reviews. 14 (2001) 244-269. https://doi.org/10.1128/CMR.14.2.244-269.2001.

[3] A.C.D.O. Gonzalez, Z.D.A. Andrade, T.F. Costa, A.R.A.P. Medrado, Wound healing - A literature review, Anais Brasileiros de Dermatologia. 91 (2016) 614-620. https://doi.org/10.1590/abd18064841.20164741.

[4] H.N. Wilkinson, M.J. Hardman, Wound healing: cellular mechanisms and pathological outcomes: Cellular Mechanisms of Wound Repair, Open Biology. 10 (2020). https://doi.org/10.1098/rsob.200223.

[5] E.M. Tottoli, R. Dorati, I. Genta, E. Chiesa, S. Pisani, B. Conti, Skin wound healing process and new emerging technologies for skin wound care and regeneration, Pharmaceutics. 12 (2020) 1-30. https://doi.org/10.3390/pharmaceutics12080735.

[6] O. Sarheed, A. Ahmed, D. Shouqair, J. Boateng, Antimicrobial Dressings for Improving Wound Healing, Wound Healing - New Insights into Ancient Challenges. (2016). https://doi.org/10.5772/63961.

[7] N.C. Das, B. Roy, R. Patra, Surface-Modi fi ed Noble Metal Nanoparticles as Antimicrobial Agents: Biochemical , Molecular and Therapeutic Perspectives, n.d.

[8] J. Talapko, T. Matijević, M. Juzbašić, A. Antolović-Požgain, I. Škrlec, Antibacterial activity of silver and its application in dentistry, cardiology and dermatology, Microorganisms. 8 (2020) 1-13. https://doi.org/10.3390/microorganisms8091400. 
[9] F. Paladini, M. Pollini, Antimicrobial silver nanoparticles for wound healing application: Progress and future trends, Materials. 12 (2019). https://doi.org/10.3390/ma12162540.

[10] Y. Qing, L. Cheng, R. Li, G. Liu, Y. Zhang, X. Tang, J. Wang, H. Liu, Y. Qin, Potential antibacterial mechanism of silver nanoparticles and the optimization of orthopedic implants by advanced modification technologies, International Journal of Nanomedicine. 13 (2018) 3311-3327. https://doi.org/10.2147/IJN.S165125.

[11] P.D. Krishnan, D. Banas, R.D. Durai, D. Kabanov, B. Hosnedlova, M. Kepinska, C. Fernandez, B. Ruttkay-Nedecky, H.V. Nguyen, A. Farid, J. Sochor, V.H.B. Narayanan, R. Kizek, Silver nanomaterials for wound dressing applications, Pharmaceutics. 12 (2020) 1-27. https://doi.org/10.3390/pharmaceutics12090821.

[12] H. Pangli, S. Vatanpour, S. Hortamani, R. Jalili, A. Ghahary, Incorporation of Silver Nanoparticles in Hydrogel Matrices for Controlling Wound Infection, Journal of Burn Care \& Research. (2020) 1-9. https://doi.org/10.1093/jbcr/iraa205.

[13] K. Zhang, V.C.H. Lui, Y. Chen, C.N. Lok, K.K.Y. Wong, Delayed application of silver nanoparticles reveals the role of early inflammation in burn wound healing, Scientific Reports. 10 (2020) 1-12. https://doi.org/10.1038/s41598-020-63464-z.

[14] P.J. Kondiah, Y.E. Choonara, P.P.D. Kondiah, T. Marimuthu, P. Kumar, L.C. Du Toit, V. Pillay, A review of injectable polymeric hydrogel systems for application in bone tissue engineering, Molecules. 21 (2016). https://doi.org/10.3390/molecules21111580.

[15] H. Tan, K.G. Marra, Injectable, biodegradable hydrogels for tissue engineering applications, Materials. 3 (2010) 1746-1767. https://doi.org/10.3390/ma3031746.

[16] M.K. Nguyen, D.S. Lee, Injectable biodegradable hydrogels, Macromolecular Bioscience. 10 (2010) 563-579. https://doi.org/10.1002/mabi.200900402.

[17] W. Xu, X. Wang, N. Sandler, S. Willför, C. Xu, Three-Dimensional Printing of Wood-Derived Biopolymers: A Review Focused on Biomedical Applications, ACS Sustainable Chemistry and Engineering. 6 (2018) 5663-5680. https://doi.org/10.1021/acssuschemeng.7b03924.

[18] M.C. Tate, D.A. Shear, S.W. Hoffman, D.G. Stein, M.C. LaPlaca, Biocompatibility of methylcellulosebased constructs designed for intracerebral gelation following experimental traumatic brain injury, Biomaterials. 22 (2001) 1113-1123. https://doi.org/10.1016/S0142-9612(00)00348-3.

[19] J. Desbrières, M. Hirrien, S.B. Ross-Murphy, Thermogelation of methylcellulose: Rheological considerations, Polymer. 41 (2000) 2451-2461. https://doi.org/10.1016/S0032-3861(99)00413-9.

[20] S.D. Dutta, D.K. Patel, K.T. Lim, Functional cellulose-based hydrogels as extracellular matrices for tissue engineering, Journal of Biological Engineering. 13 (2019) 1-19. https://doi.org/10.1186/s13036- 
[21] J. Li, C. Wu, P.K. Chu, M. Gelinsky, 3D printing of hydrogels: Rational design strategies and emerging biomedical applications, Materials Science and Engineering R: Reports. 140 (2020) 100543. https://doi.org/10.1016/j.mser.2020.100543.

[22] A. Ali, S. Ahmed, Recent Advances in Edible Polymer Based Hydrogels as a Sustainable Alternative to Conventional Polymers, Journal of Agricultural and Food Chemistry. 66 (2018) 6940-6967. https://doi.org/10.1021/acs.jafc.8b01052.

[23] M. Dovedytis, Z.J. Liu, S. Bartlett, Hyaluronic acid and its biomedical applications: A review, Engineered Regeneration. 1 (2020) 102-113. https://doi.org/10.1016/j.engreg.2020.10.001.

[24] D. Ruhela, K. Riviere, F.C. Szoka, Efficient synthesis of an aldehyde functionalized hyaluronic acid and its application in the preparation of hyaluronan-lipid conjugates, Bioconjugate Chemistry. 17 (2006) 1360-1363. https://doi.org/10.1021/bc0600721.

[25] M.A. Garza-Navarro, J.A. Aguirre-Rosales, E.E. Llanas-Vázquez, I.E. Moreno-Cortez, A. Torres-Castro, V. González-González, Totally ecofriendly synthesis of silver nanoparticles from aqueous dissolutions of polysaccharides, International Journal of Polymer Science. 2013 (2013).

https://doi.org/10.1155/2013/436021.

[26] C. Dong, X. Zhang, H. Cai, Green synthesis of monodisperse silver nanoparticles using hydroxy propyl methyl cellulose, Journal of Alloys and Compounds. 583 (2014) 267-271.

https://doi.org/10.1016/j.jallcom.2013.08.207.

[27] T. Suwan, S. Khongkhunthian, S. Okonogi, Silver nanoparticles fabricated by reducing property of cellulose derivatives, Drug Discoveries \& Therapeutics. 13 (2019) 70-79.

https://doi.org/10.5582/ddt.2019.01021.

[28] A.K.M.F. Lustosa, A.C. De Jesus Oliveira, P.V. Quelemes, A. Plácido, F.V. Da Silva, I.S. Oliveira, M.P. De Almeida, A. das G.N. Amorim, C. Delerue-Matos, R. de C.M. de Oliveira, D.A. da Silva, P. Eaton, J.R. de Souza de Almeida Leite, In situ synthesis of silver nanoparticles in a hydrogel of carboxymethyl cellulose with phthalated-cashew gum as a promising antibacterial and healing agent, International Journal of Molecular Sciences. 18 (2017). https://doi.org/10.3390/ijms18112399.

[29] M.A. Pedroza-Toscano, S. López-Cuenca, M. Rabelero-Velasco, E.D. Moreno-Medrano, A.P. Mendizabal-Ruiz, R. Salazar-Peña, Silver Nanoparticles Obtained by Semicontinuous Chemical Reduction Using Carboxymethyl Cellulose as a Stabilizing Agent and Its Antibacterial Capacity, Journal of Nanomaterials. 2017 (2017). https://doi.org/10.1155/2017/1390180.

[30] P. Sarkar, D.K. Bhui, H. Bar, G.P. Sahoo, S. Samanta, S. Pyne, A. Misra, Aqueous-Phase Synthesis of Silver Nanodiscs and Nanorods in Methyl Cellulose Matrix: Photophysical Study and Simulation of UV- 
Vis Extinction Spectra Using DDA Method, Nanoscale Research Letters. 5 (2010) 1611-1618. https://doi.org/10.1007/s11671-010-9684-0.

[31] M.L. Coughlin, L. Liberman, S.P. Ertem, J. Edmund, F.S. Bates, T.P. Lodge, Methyl cellulose solutions and gels: fibril formation and gelation properties, Progress in Polymer Science. 112 (2021) 101324. https://doi.org/10.1016/j.progpolymsci.2020.101324.

[32] F.R. Diniz, R.C.A.P. Maia, L. Rannier, L.N. Andrade, M. V. Chaud, C.F. da Silva, C.B. Corrêa, R.L.C. de Albuquerque Junior, L.P. da Costa, S.R. Shin, S. Hassan, E. Sanchez-Lopez, E.B. Souto, P. Severino, Silver nanoparticles-composing alginate/gelatine hydrogel improves wound healing in vivo, Nanomaterials. 10 (2020). https://doi.org/10.3390/nano10020390.

[33] L. Dai, B. Nadeau, X. An, D. Cheng, Z. Long, Y. Ni, Silver nanoparticles-containing dual-function hydrogels based on a guar gum-sodium borohydride system, Scientific Reports. 6 (2016) 7-12. https://doi.org/10.1038/srep36497.

[34] J. Baukum, J. Pranjan, A. Kaolaor, P. Chuysinuan, O. Suwantong, P. Supaphol, The potential use of cross-linked alginate/gelatin hydrogels containing silver nanoparticles for wound dressing applications, Polymer Bulletin. 77 (2020) 2679-2695. https://doi.org/10.1007/s00289-019-02873-1.

[35] H. Jiang, G. Zhang, B. Xu, X. Feng, Q. Bai, G. Yang, H. Li, Thermosensitive antibacterial Ag nanocomposite hydrogels made by a one-step green synthesis strategy, New Journal of Chemistry. 40 (2016) 6650-6657. https://doi.org/10.1039/c5nj03608a.

[36] M. Tanaka, T. Hayashi, S. Morita, The roles of water molecules at the biointerface of medical polymers, Polymer Journal. 45 (2013) 701-710. https://doi.org/10.1038/pj.2012.229.

[37] K. Nešović, V. Mišković-Stanković, A comprehensive review of the polymer-based hydrogels with electrochemically synthesized silver nanoparticles for wound dressing applications, Polymer Engineering and Science. 60 (2020) 1393-1419. https://doi.org/10.1002/pen.25410.

[38] M. Ider, K. Abderrafi, A. Eddahbi, S. Ouaskit, A. Kassiba, Silver Metallic Nanoparticles with Surface Plasmon Resonance: Synthesis and Characterizations, Journal of Cluster Science. 28 (2017) 1051-1069. https://doi.org/10.1007/s10876-016-1080-1.

[39] M.T.S. Alcântara, N. Lincopan, P.M. Santos, P.A. Ramirez, A.J.C. Brant, H.G. Riella, A.B. Lugão, Simultaneous hydrogel crosslinking and silver nanoparticle formation by using ionizing radiation to obtain antimicrobial hydrogels, Radiation Physics and Chemistry. 169 (2020) 108777. https://doi.org/10.1016/j.radphyschem.2020.108777.

[40] C. Dai, Y. Li, W. Pan, G. Wang, R. Huang, Y. Bu, X. Liao, K. Guo, F. Gao, Three-Dimensional HighPorosity Chitosan/Honeycomb Porous Carbon/Hydroxyapatite Scaffold with Enhanced Osteoinductivity 
for Bone Regeneration, ACS Biomaterials Science and Engineering. 6 (2020) 575-586. https://doi.org/10.1021/acsbiomaterials.9b01381.

[41] S. Agnihotri, S. Mukherji, S. Mukherji, Antimicrobial chitosan-PVA hydrogel as a nanoreactor and immobilizing matrix for silver nanoparticles, Applied Nanoscience. 2 (2012) 179-188. https://doi.org/10.1007/s13204-012-0080-1.

[42] J. Song, Y. Zhu, J. Zhang, J. Yang, Y. Du, W. Zheng, C. Wen, Y. Zhang, L. Zhang, Encapsulation of AgNPs within Zwitterionic Hydrogels for Highly Efficient and Antifouling Catalysis in Biological Environments, Langmuir. 35 (2019) 1563-1570. https://doi.org/10.1021/acs.langmuir.8b02918.

[43] Y.A.R. Nuñez, R.I. Castro, F.A. Arenas, Z.E. López-Cabaña, G. Carreño, V. Carrasco-Sánchez, A. Marican, J. Villaseñor, E. Vargas, L.S. Santos, E.F. Durán-Lara, Preparation of hydrogel/silver nanohybrids mediated by tunable-size silver nanoparticles for potential antibacterial applications, Polymers. 11 (2019). https://doi.org/10.3390/polym11040716.

[44] S. Agnihotri, S. Mukherji, S. Mukherji, Size-controlled silver nanoparticles synthesized over the range 5-100 nm using the same protocol and their antibacterial efficacy, RSC Advances. 4 (2014) 3974-3983. https://doi.org/10.1039/c3ra44507k.

[45] R.L. Oliveira, J.G. Vieira, H.S. Barud, R.M.N. Assunção, G.R. Filho, S.J.L. Ribeiro, Y. Messadeqq, Synthesis and characterization of methylcellulose produced from bacterial cellulose under heterogeneous condition, Journal of the Brazilian Chemical Society. 26 (2015) 1861-1870. https://doi.org/10.5935/0103-5053.20150163.

[46] A. Sannino, S. Pappadà, M. Madaghiele, A. Maffezzoli, L. Ambrosio, L. Nicolais, Crosslinking of cellulose derivatives and hyaluronic acid with water-soluble carbodiimide, Polymer. 46 (2005) 1120611212. https://doi.org/10.1016/j.polymer.2005.10.048.

[47] G.Z.S. Oliveira, C.A.P. Lopes, M.H. Sousa, L.P. Silva, Synthesis of silver nanoparticles using aqueous extracts of Pterodon emarginatus leaves collected in the summer and winter seasons, International Nano Letters. 9 (2019) 109-117. https://doi.org/10.1007/s40089-019-0265-7.

[48] K. Yu, F. Lu, Q. Li, H. Chen, B. Lu, J. Liu, Z. Li, F. Dai, D. Wu, G. Lan, In situ assembly of Ag nanoparticles (AgNPs) on porous silkworm cocoon-based would film: Enhanced antimicrobial and wound healing activity, Scientific Reports. 7 (2017) 1-13. https://doi.org/10.1038/s41598-017-02270-6.

[49] T.D. Nguyen, T.T. Nguyen, K.L. Ly, A.H. Tran, T.T.N. Nguyen, M.T. Vo, H.M. Ho, N.T.N. Dang, V.T. Vo, D.H. Nguyen, T.T.H. Nguyen, T.H. Nguyen, In vivo study of the antibacterial chitosan/polyvinyl alcohol loaded with silver nanoparticle hydrogel for wound healing applications, International Journal of Polymer Science. 2019 (2019). https://doi.org/10.1155/2019/7382717. 
[50] A. Gupta, S.M. Briffa, S. Swingler, H. Gibson, V. Kannappan, G. Adamus, M. Kowalczuk, C. Martin, I. Radecka, Synthesis of Silver Nanoparticles Using Curcumin-Cyclodextrins Loaded into Bacterial CelluloseBased Hydrogels for Wound Dressing Applications, Biomacromolecules. 21 (2020) 1802-1811. https://doi.org/10.1021/acs.biomac.9b01724.

[51] Y. Niu, T. Guo, X. Yuan, Y. Zhao, L. Ren, An injectable supramolecular hydrogel hybridized with silver nanoparticles for antibacterial application, Soft Matter. 14 (2018) 1227-1234. https://doi.org/10.1039/c7sm02251d.

[52] D.S. Mohamed, R.M.A. El-Baky, T. Sandle, S.A. Mandour, E.F. Ahmed, Antimicrobial activity of silvertreated bacteria against other multi-drug resistant pathogens in their environment, Antibiotics. 9 (2020). https://doi.org/10.3390/antibiotics9040181.

[53] Y.N. Slavin, J. Asnis, U.O. Häfeli, H. Bach, Metal nanoparticles: Understanding the mechanisms behind antibacterial activity, Journal of Nanobiotechnology. 15 (2017) 1-20. https://doi.org/10.1186/s12951-017-0308-z.

[54] K. Kalantari, E. Mostafavi, A.M. Afifi, Z. Izadiyan, H. Jahangirian, R. Rafiee-Moghaddam, T.J. Webster, Wound dressings functionalized with silver nanoparticles: Promises and pitfalls, Nanoscale. 12 (2020) 2268-2291. https://doi.org/10.1039/c9nr08234d.

[55] N.K. Rajendran, S.S.D. Kumar, N.N. Houreld, H. Abrahamse, A review on nanoparticle based treatment for wound healing, Journal of Drug Delivery Science and Technology. 44 (2018) 421-430. https://doi.org/10.1016/j.jddst.2018.01.009.

[56] N. Masood, R. Ahmed, M. Tariq, Z. Ahmed, M.S. Masoud, I. Ali, R. Asghar, A. Andleeb, A. Hasan, Silver nanoparticle impregnated chitosan-PEG hydrogel enhances wound healing in diabetes induced rabbits, International Journal of Pharmaceutics. 559 (2019) 23-36.

https://doi.org/10.1016/j.ijpharm.2019.01.019.

[57] G. Tao, R. Cai, Y. Wang, L. Liu, H. Zuo, P. Zhao, A. Umar, C. Mao, Q. Xia, H. He, Bioinspired design of AgNPs embedded silk sericin-based sponges for efficiently combating bacteria and promoting wound healing, Materials and Design. 180 (2019) 107940. https://doi.org/10.1016/j.matdes.2019.107940.

[58] G. Nam, S. Rangasamy, B. Purushothaman, J.M. Song, The application of bactericidal silver nanoparticles in wound treatment, Nanomaterials and Nanotechnology. 5 (2015). https://doi.org/10.5772/60918.

[59] J. Tian, K.K.Y. Wong, C.M. Ho, C.N. Lok, W.Y. Yu, C.M. Che, J.F. Chiu, P.K.H. Tam, Topical delivery of silver nanoparticles promotes wound healing, ChemMedChem. 2 (2007) 129-136. https://doi.org/10.1002/cmdc.200600171. 
[60] M. Liu, G. Luo, Y. Wang, R. Xu, Y. Wang, W. He, J. Tan, M. Xing, J. Wu, Nano-silver-decorated microfibrous eggshell membrane: Processing, cytotoxicity assessment and optimization, antibacterial activity and wound healing, Scientific Reports. 7 (2017) 1-14. https://doi.org/10.1038/s41598-01700594-x.

[61] F.F. Larese, F. D’Agostin, M. Crosera, G. Adami, N. Renzi, M. Bovenzi, G. Maina, Human skin penetration of silver nanoparticles through intact and damaged skin, Toxicology. 255 (2009) 33-37. https://doi.org/10.1016/j.tox.2008.09.025.

[62] A. Kaler, A.K. Mittal, M. Katariya, H. Harde, A.K. Agrawal, S. Jain, U.C. Banerjee, An investigation of in vivo wound healing activity of biologically synthesized silver nanoparticles, Journal of Nanoparticle Research. 16 (2014). https://doi.org/10.1007/s11051-014-2605-x.

\section{Figures}
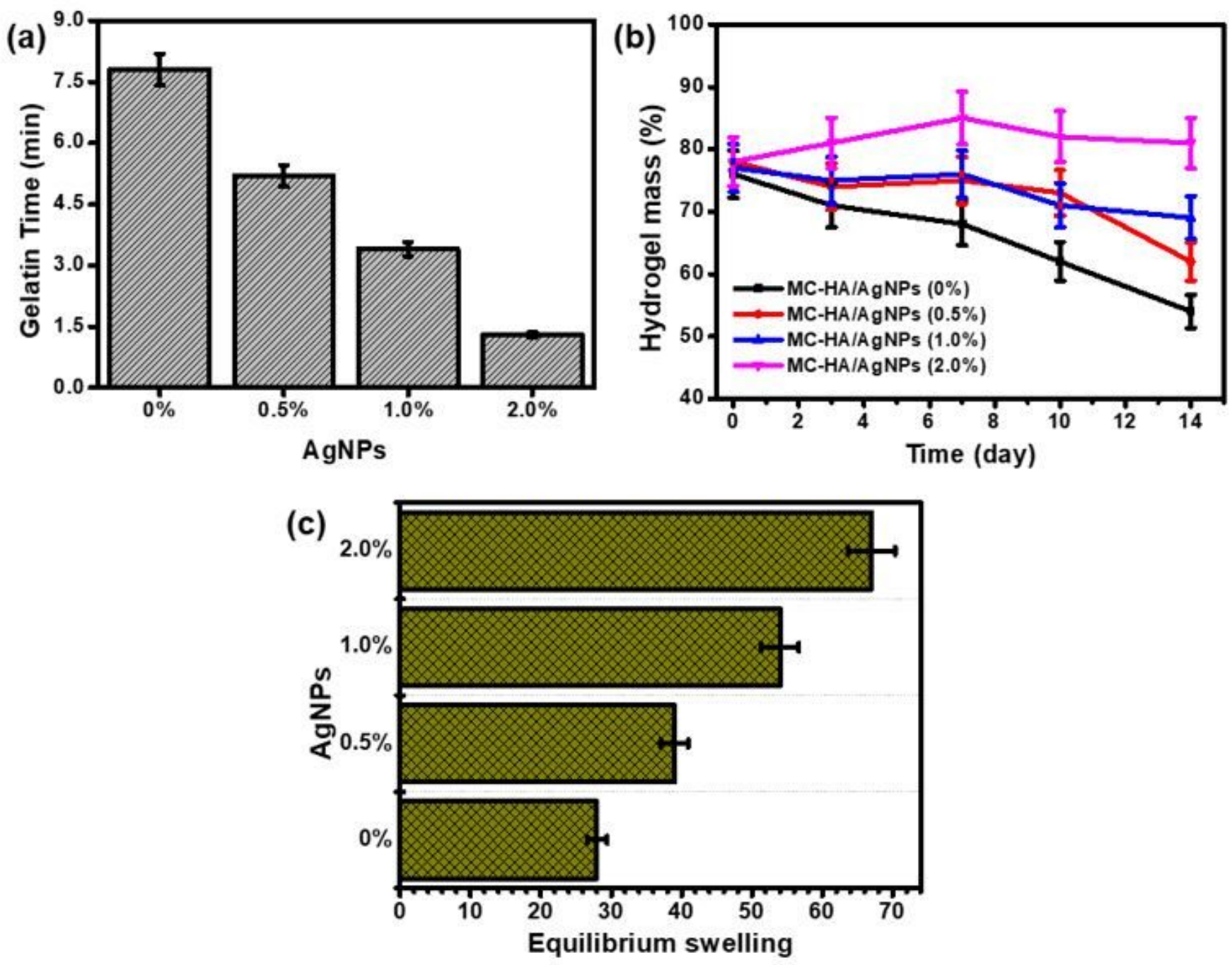

Figure 1 
(a) Gelation time, (b) In vitro degradation, and (c) equilibrium swelling ratio of MC-HA hydrogels as a function of AgNPs ratio.

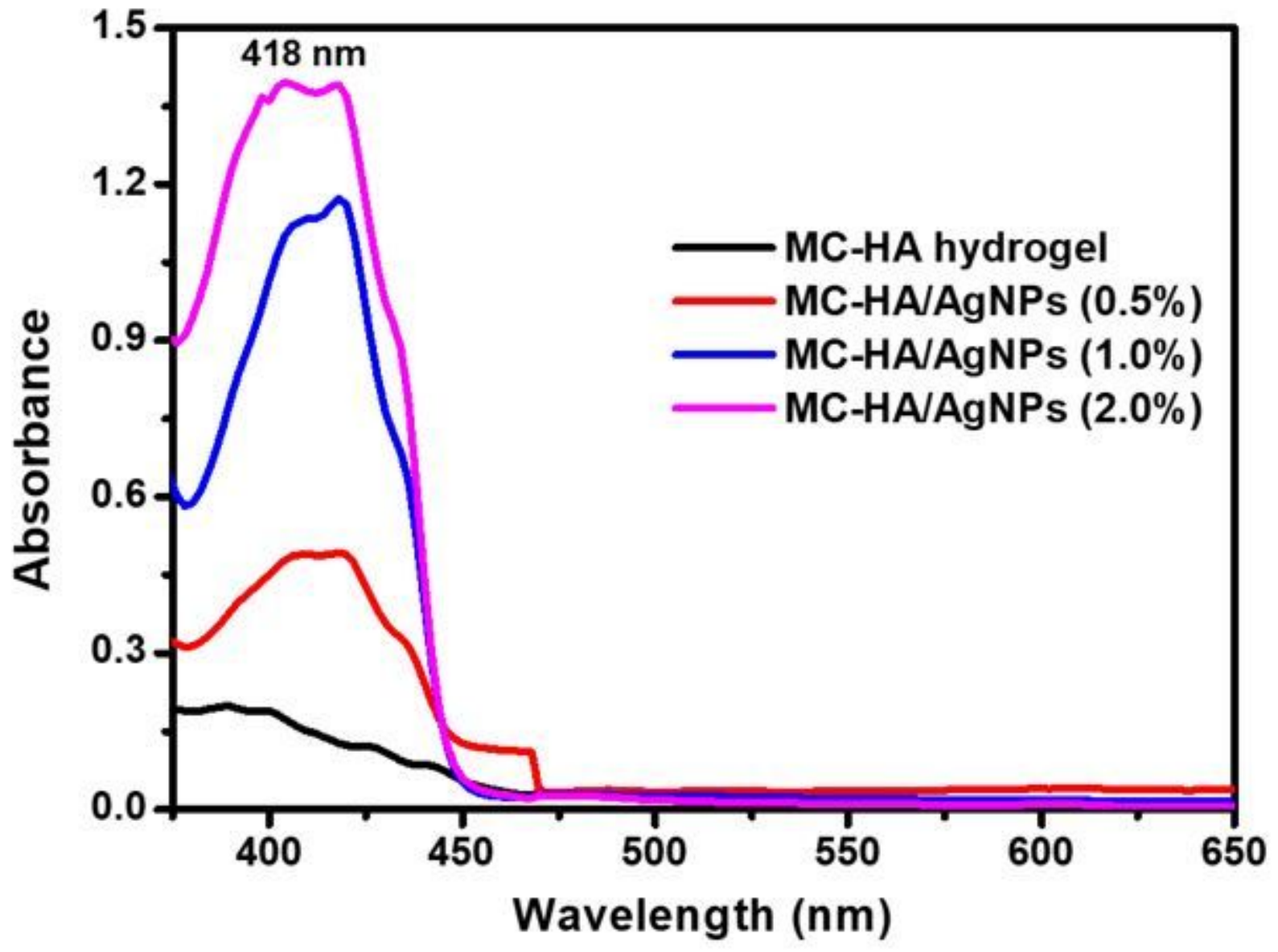

Figure 2

UV-vis absorption spectra of MC-HA hydrogels containing AgNPs at different concentrations $(0.5,1.0$, and $2.0 \% \mathrm{w} / \mathrm{w})$. 

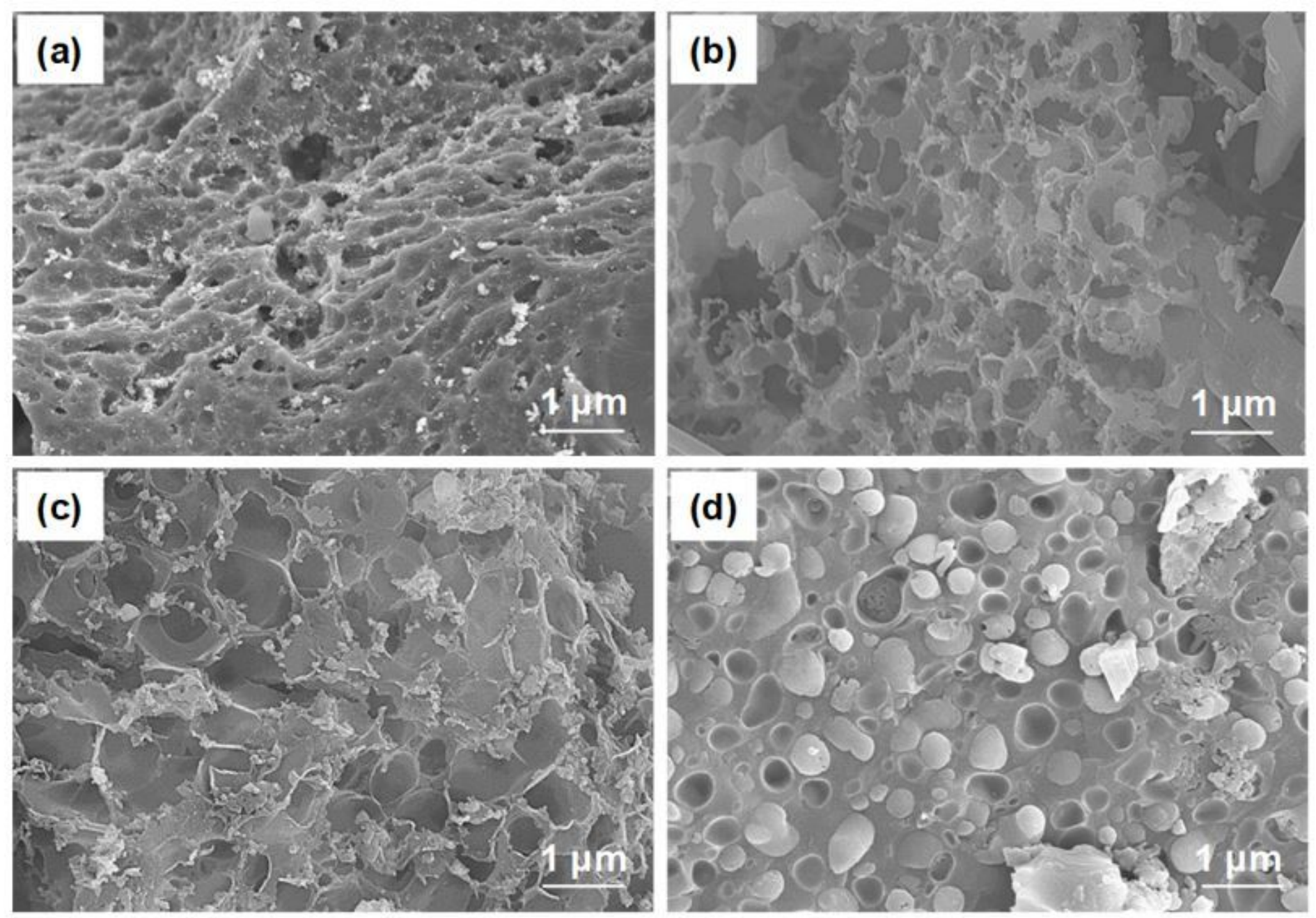

Figure 3

SEM images of MC-HA hydrogel (a) and MC-HA hydrogel containing AgNPs (b) $0.5 \%$, (c) $1.0 \%$, and (d) $2.0 \%$. 

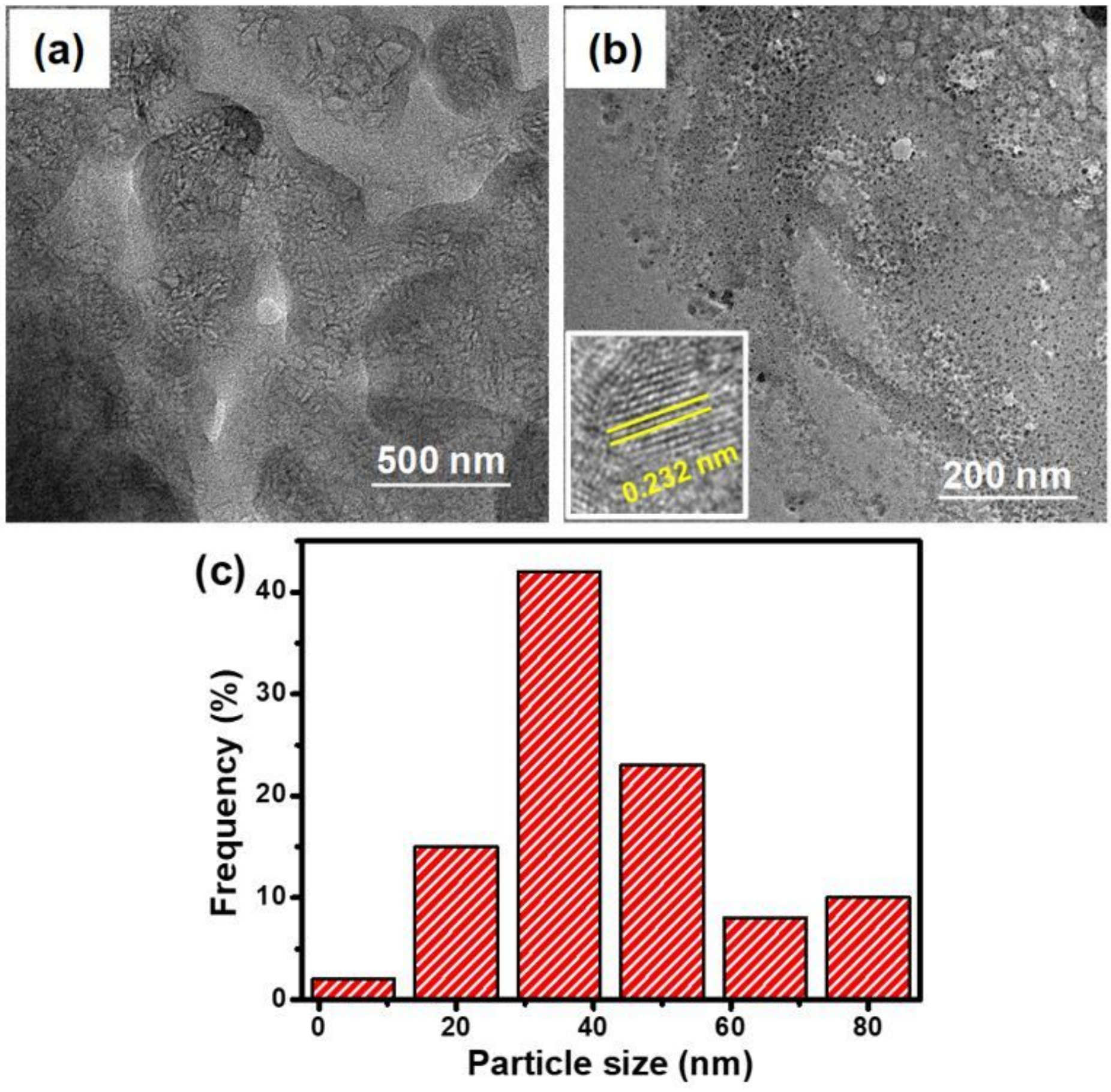

Figure 4

TEM images of MC-HA hydrogel (a), MC-HA hydrogel containing AgNPs (b) with inset figure; HRTEM lattice springe of AgNPs, and Histogram image the average sizes of MC-HA hydrogel containing AgNPs (c). 

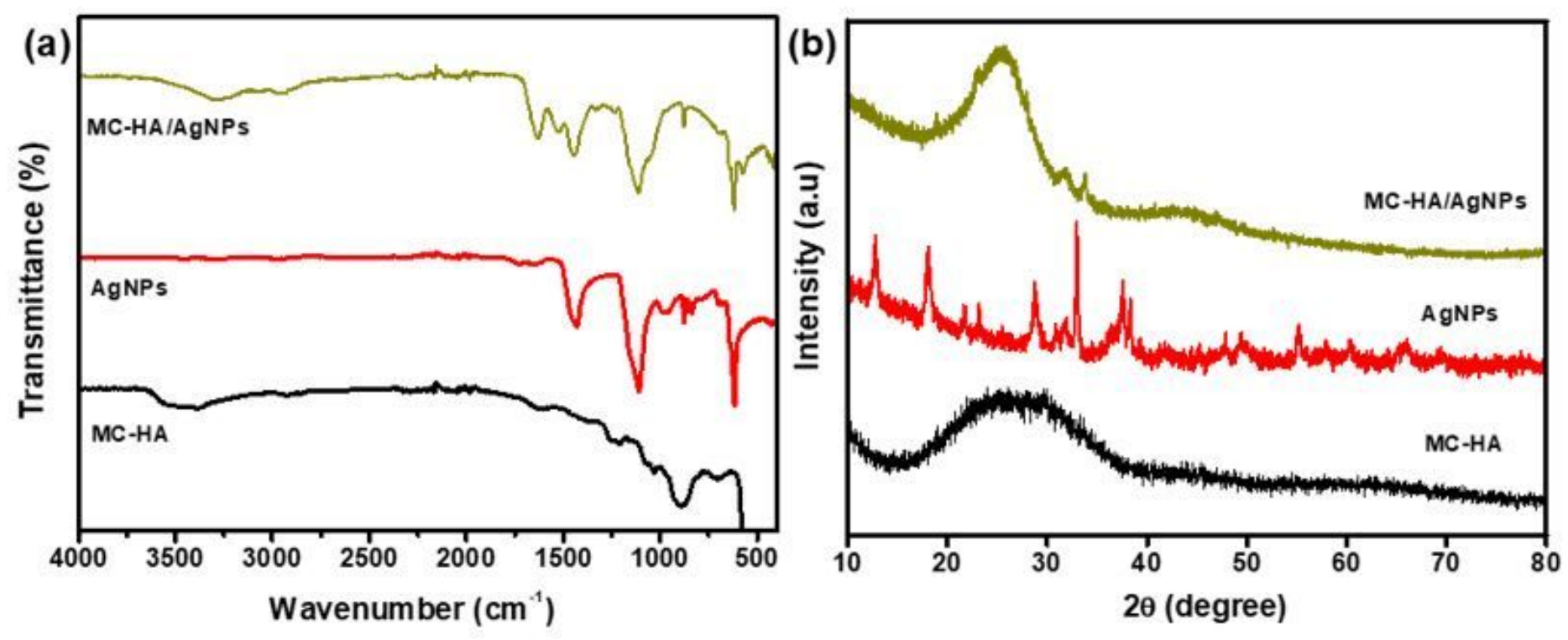

Figure 5

(a) FTIR spectra and (b) XRD patterns of the MC-HA hydrogel, AgNPs, and MC-HA/ AgNPs hydrogel.
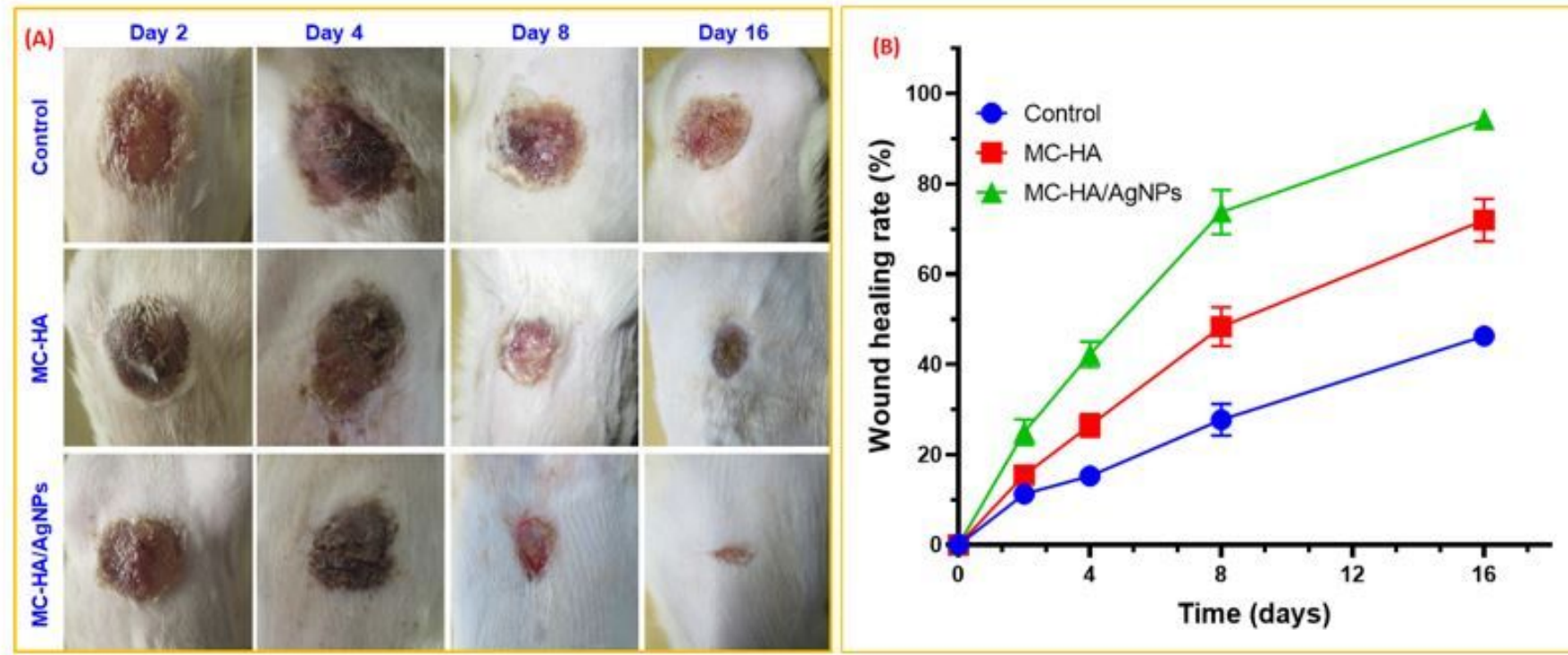

Figure 6

(a) In vivo study of control, MC-HA, and MC-HA/AgNPs as a wound dressing and (b) the evaluation of wound healing rate (\%). 

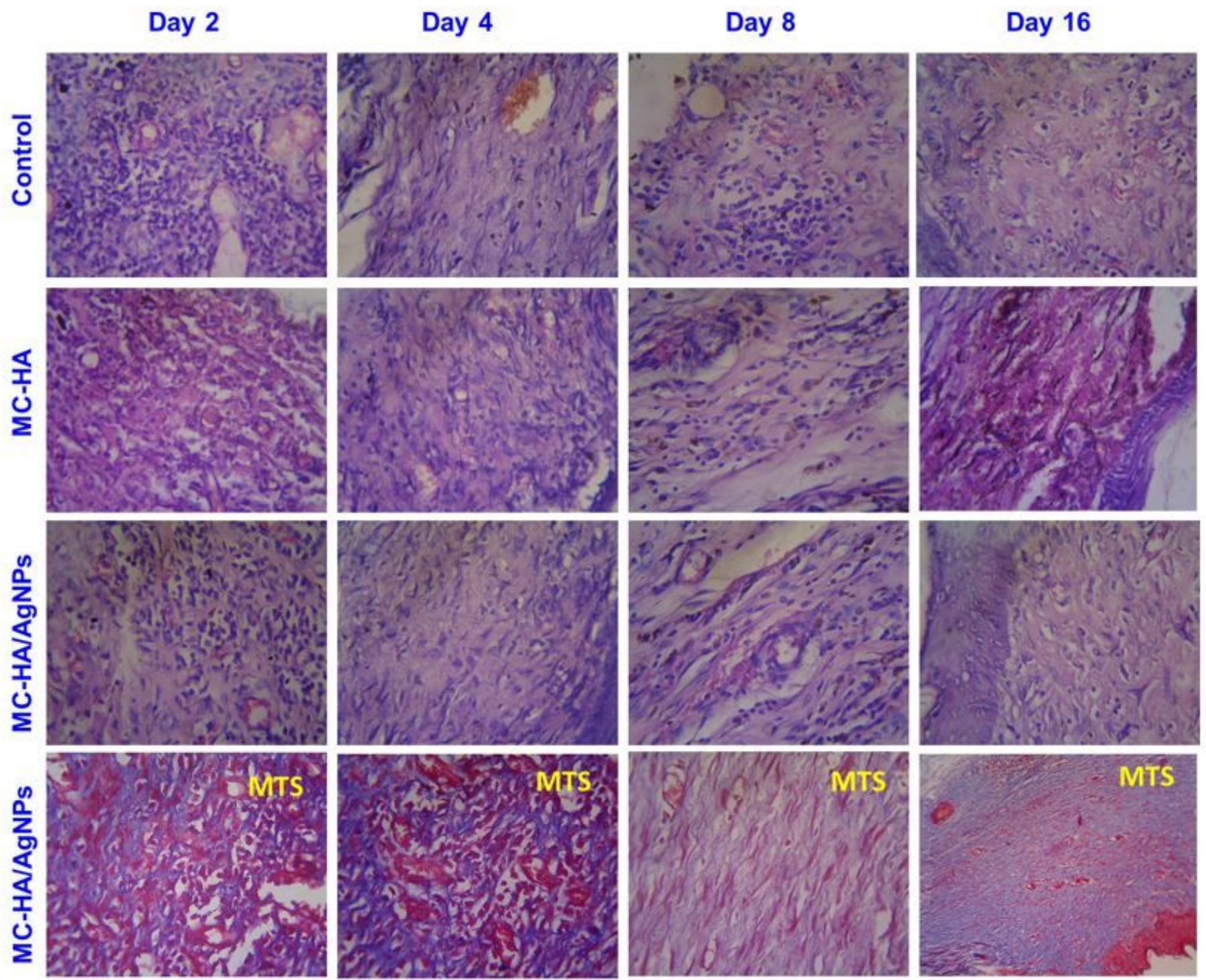

\section{Figure 7}

Hematoxylin and eosin (H\&E)-stained and MTS-stained sections of the granulation tissue of control, MC$\mathrm{HA}$, and MC-HA/AgNPs on postoperative day 2, 4, 8 and 16. 